\title{
A NORMATIZAÇÃO DO PROJETO POLÍTICO DE ALFONSO X: "LAS SIETE PARTIDAS"
}

Ana Beatriz Frazão Ribeiro*

SÍNTESE - Alfonso X, o sábio, monarca castelano do século XIII, patrocinou uma produção intelectual de grande envergadura em todos os campos do conhecimento. No grupo de obras políticas, destaca-se como sua produçäo mais importante "Las Siete Partidas". Influenciada pelo Direito Romano, esta obra visa constituir um código legal com amplitude superior aos antigos fueros locais. Objetivamos estudar como "Las Siete Partidas" desvelam as aspirações políticas do Rei Sábio, ou seja, o reforço do poder real, sua autoridade como monarca, através da elaboração de uma linha teórica que vise a coesão das leis.

\begin{abstract}
The sage Castilian monarch of the XIII century sponsored an intellectual production of great importance in all the fields of knowledge. Among his political writings the most important is "Las Siete Partidas". Influenced by the Roman Law this writing aimed to establish a legal code superior to the old "fueros" with regional character. We aim to study how "Las Siete Partidas" reveals the political intentions of the sage king, in other words, the reinforcement of the royal power, his authority as a monarch, through the organization of a theoretical line that aimes to unify the laws.
\end{abstract}

No século XIII, na Península Ibérica, destaca-se a figura do monarca castelano Alfonso X, o sábio. Filho e herdeiro de Fernando III, torna-se rei de Leão e Castela exercendo seu poderio sobre estes reinos, cada vez mais unidos, e também sobre os territórios conquistados aos muçulmanos e incorporados ao domínio cristão.

Como homem de seu tempo, Alfonso X foi influenciado pelo renascimento cultural ocorrido no século XIII: época de aumento dos centros urbanos, florescimento do comércio, crescimento das universidades e desenvolvimento em todos os niveis da produção intelectual. Sobre a época de Alfonso X, Robert Burns afirma:

\begin{abstract}
"De modo paradógico, toda la promesa contenida en el Renacimiento del siglo XII floreció entonces en grandes obras de derecho, filosofia, religión, medicina, letras, traducciones, viajes, tecnología y artes. [...] Hombres como el filósofo Tomás de Aquino, el poeta Dante, el navegante y mercader Marco Polo, y el genio religioso de Francisco de Asís".
\end{abstract}

No que se refere ao campo jurídico, o século XIII foi marcado pelo desenvolvimento da atividade legislativa inspirada no Direito Romano, influenciado pelo Có-

* Universidade Federal do Rio de Janeiro - UFRJ.

\begin{tabular}{|l|l|l|l|l|l|}
\hline VERITAS & Porto Alegre & v. 40 & $\mathrm{n}^{2} 159$ & Setembro 1995 & p. $545-558$ \\
\hline
\end{tabular}


digo de Justiniano, utilizado como substrato legal ao fortalecimento das monarquias.

Alfonso X utilizará este cabedal de informações jurídicas no sentido de fortalecer seu poder no âmbito peninsular.

Segundo Júlio Valdeón, especialista em Idade Média peninsular, "fue en el terreno de la acción jurídico-política donde la obra de Alfonso $\mathrm{X}$ alcanzó mayor brillantez. Con este monarca irrumpió definitivamente en tierras castellano-leonesas el Derecho Romano."

O Direito Romano significará para este monarca um apoio legal favorecedor da unificação jurídica: "El caudal de ideas y de conceptos que ofrecía el romanismo era inmenso contribuyendo poderosamente al afianzamento de los poderes del príncipe $y$, en definitiva, al fortalecimento de las monarquías, ${ }^{2}$ continua dizendo Júlio Valdeón.

Sua produção jurídica está centrada em três obras principais: o Espéculo, o Fuero Real e Las Siete Partidas. O objetivo deste monarca ao elaborar estas obras é, na opinião de Pérez-Prendes:

"[...] intentado construir con su obra legislativa de Espéculo y Partidas (usando del Derecho común para sistematizar, completar, sustituir o interpretar el Derecho castellano-leonés, que de todo hay en esos textos) un edificio jurídico escrito que oponer en la práctica diaria al hueco que suponía la no fijación por escrito del régimen jurídico nobiliario." ${ }^{3}$

Las Siete Partidas ou Partidas destacam-se como a obra jurídica mais abrangente de Alfonso $\mathrm{X}$ ao conter regras relativas à vida da Igreja, monarquia, justiça, entre outras muitas.

A denominação Sete Partidas deve-se ao significado mágico atribuído ao número sete. Dividida em sete partes, cada uma trata de um tema específico. Elaborada em duas versões, a primeira em 1263 e a segunda em 1265, cada Partida possui um título iniciado por uma das letras que ao se juntarem formam a palavra ALFONSO. As Partidas estão divididas em títulos gerais, subdivididos em leis, encabeçadas por uma epigrafe. Esta divisão, comum aos tratados medievais, representa uma disposição favorável para consulta de livros ou códigos.

Esta obra significou uma tentativa de unificação legislativa influenciada pelo Direito Romano. Aos antigos Fueros usuais em Castela, baseados no direito consuetudinário, impõem-se a lei escrita com extensão para todo reino.

"Las fuentes en que bebieron los redactores de las Partidas son asimismo amplísimas, pero sobresale, por el peso de su aportación, el Derecho Romano y el Derecho Canónico. Por eso se ha considerado tradicionalmente a las Partidas, obra escrita por lo demás con un estilo impecable, como el vehículo por excelencia a través del cual penetró en la corona de Castilla el Derecho Romano".

1 VALDEÓN, Júlio et al. "La España de Alfonso X". In: Cuademos História 16. Madrid: 1985, vol. 13, p. 14.

2 Idem, Ibidem, p. 6.

3 PÉREZ - PRENDES MUÑOZ DE ARRACO, José Manuel. "Derecho y Poder". In: SALVADOR DE MOXÓ e LADERO QUESADA, Miguel Angel (coord.) Historia General de España y América. La España de los Cinco Reinos (1085 - 1369). Madrid: Rialp, 1984, T IV, p38.

4 VALDEÓN, Júlio. Alfonso X el Sabio. Valladolid: Junta de Castilla y Leon, 1986, p. 32 - 33. 
O objeto de nosso interesse é o estudo da Partida Segunda "que fabla de los enperadores e de los Reyes e de los otros grandes sennores de las cosas que an de mantener e guardar con justiçia e con verdat". ${ }^{5}$ Nesta encontramos descrito o poder real, como é exercido, de onde é proveniente e qual a sua importância.

Objetivamos analisar como Alfonso X utiliza esta obra jurídica no sentido de justificar suas idéias sobre o poder. Para isso utiliza vários recursos que vão desde a justificativa divina deste até a importância da formação do rei para que possa assumir tal cargo.

Dividimos o estudo destes recursos em sete ítens:

1. A figura do monarca e o representante de Deus.

2. A definição da nomenclatura e a explicação da função.

3. $O$ bem comum e a justiça.

4. A ajuda dos sábios e a sapientia.

5. A formação do monarca e o preparo para a virtude.

6. Comparação e caráter didático.

7. O apoio e auxilio no governo.

\section{1-A figura do monarca e o representante de Deus}

O poder espiritual encontra-se descrito na Partida Primeira que trata dos aspectos religiosos. Este é destinado aos membros da Igreja. O poder temporal merece destaque na Partida Segunda, objeto de nosso estudo. Cabe a reis e imperadores o exercício do poder temporal. Alfonso X usa o poder temporal como forma de fortalecer sua posição política.

"Conviene no olvidar que, en tiempos del rey Sabio, la Europa cristiana estaba dominada por la "teoría descendente del poder político", según la cual los monarcas recibian su oficio directamente de Dios, fuente originaria de todo poder. Una de las facetas a través de las cuales se expresaba la voluntas principis era precisamente la promulgación de leyes." ${ }^{66}$

O monarca é descrito como um representante fundamental para manutenção da ordem e da justiça para que todos vivam de forma correta e segundo os designos divinos. São estas as palavras do Rei Sábio:

"por ende nuestro sennor Dios puso otro poder tenporal en la tierra en que esto se cunpliese, asy commo la justiçia que quiso que se fiziese en la tierra por mano de los enperadores e de los otros Reyes. E estas son las dos espadas por que el mundo se mantiene, la una espiritual e la otra tenporal, ca la espiritual toie los males ascondudos, e la tenporal los manifiestos" (PII, introdução).

Ao poder temporal cabe impedir as manifestações de males no mundo dos homens. Deve cumprir com justiça. Este poder foi-lhe imposto por Deus para que atuasse da melhor forma possivel.

5 ALFONSO X Partida Segunda. Manuscrito 12794 de la B. N. Edição de Aurora Juarez Blanquer e Antonio Rubio Flores. Granada: Impredisur, 1991, p. 35. Utilizaremos esta edição da Partida Segunda em todas as citações. Para facilitar a leitura adotamos o seguinte critério: T (para Título) Ley (para a Lei). Os números que acompanham o titulo e a lei são escritos em algarismos romanos.

VALDEÓN, Júlio. Alfonso X el sabio, p. 29. 
O ser rei é uma honra concedida somente por Deus: "Ca el sennor que Dios tal onrra da es Rey [...]" (T1, Ley 1), o que torna o poder algo indiscutivel já que é um atributo concedido pelo próprio Deus. Os monarcas são designados como "Vicarios de Dios" (TI, Ley V). Estas dignidades (ser honrado por Deus, vicário de Deus) são atributos que dificultam qualquer tipo de questionamento. Duvidar deste poder significa reclamar uma atitude da divindade.

A relação do monarca com a divindade torna-se uma necessidade moral para a condução de suas ações. O rei é um homem comum, sujeito a erros. Deve manter uma relação de temor / amor a Deus:

"ca non abonda al Rey de conosçer e de amar a Dios tan sola mente, mas ha menester quel despues quel conosçiere el amare quel tema, lo uno porque es poderoso, e lo al porque es justiçiero, e demas que es tenudo de dar cuenta a el en este mundo e en el otro, porque tien su lugar en tierra" (T II, Ley III).

O temor está associado ao caráter de amor, respeito e conhecimento, fundamental a todos os mortais. Os sentimentos entre o monarca e a divindade são compartilhados por todos os súditos, que são humanos e mortais como ele.

$\mathrm{O}$ castigo é maior quanto maior for o discernimento das coisas divinas:

" $\mathrm{E}$ al que por sus malos pecados asy non lo fiziere, darle a Dios el contrario desto e serie su pena mayor que dotro omne, segunt le demostrara el grant amor en darle onrra e poder" (T II, Ley III).

Para uma maior compreensão de suas atribuições no plano terreno, é necesário ao monarca o entendimento da verdade. Este conhecimento se realiza através do caráter racional já que é o entendimento que torna o homem capaz de estar mais próximo da vontade de Deus, percebendo a realidade de forma cada vez mais apurada.

O conhecimento das coisas de Deus visa atender três objetivos: conhecer a si mesmo em suas limitações e erros no sentido de manter uma vida correta, conhecer o seu mundo ao entender a necessidade de cada um e atuar sobre este de forma a facilitar a vida na coletividade:

"ca sy destas maneras nol conosçiere, non sabran conosçer a sy mismos, ni el nonbre que a, nin el lugar que tien para fazer justicia e derecho" (T II, Ley Primera).

O monarca não tem que justificar-se perante a Igreja pelas atitudes temporais, ele será julgado por Deus. É um homem sujeito aos castigos derivados de seus erros. Tais castigos são proporcionais às falhas cometidas e ao grau de sabedoria do culpado. Sendo a sabedoria um exercício contínuo capaz de favorecer o crescimento individual, gerando uma maior consciência da função do monarca no mundo em que vive, esta deve ser utilizada para discernir o certo do errado:

"el Rey que depreçiase de aprender los saberes, despreçiaria a Dios de quien vienen todos, [...]" (T III, Ley XVI).

A sabedoria vem de Deus e cabe ao homem tentar atingir um pouco desta. Através do conhecimento dos desígnios divinos o monarca é capaz de governar não em seu interesse mas no sentido de colocá-la em prática. 
Segundo Adeline Rucquoi, "al adoptar la sabiduría divina como atributo que fundamenta su poder en la tierra, los reyes de Castilla han sido investidos con la' sapientia de Dios, que sola permite gobernar los pueblos, hacer leyes, impartir justiçia, [.... $]^{\mathrm{u}^{7}}$

A proposta de convencer está implícita na contextualização da figura do monarca como representante de Deus. É um monarca mortal, sujeito a erros e castigos. Visa, através da sabedoria, praticar o exercício da justiça, para desempenhar da melhor forma seu papel temporal, honrando o poder que lhe foi concedido. Suas atitudes não são intempestivas mas fruto de um conhecimento prévio dos interesses de seus súditos para que vivam em bondade. Sua prática é vinculada aos binômios poder/sabedoria, erro/castigo.

\section{2 - A definição da nomenclatura / a explicação da função}

Alfonso X, para elucidar a função de seu cargo, descreve o significado da palavra rei. O Título da Ley VI enuncia assim:

"Que quiere dezir Rey, e por que es asy llamado" (TI, Ley VI).

A explicação da palavra é:

"Rey tanto quiere dezir commo rrregidor, ca syn falla a el pertenesçe el governamiento del rreyno, [...]" (TI, Ley VI).

$O$ reino é adquirido de diversas maneiras, conforme pode ser confirmado pela leitura do Título da Ley IX:

"En quantas maneras se gana el rreegno derechamente" (T I, Ley IX).

São quatro as formas de ganhar o reino: por herança, por escolha, por casamento ou por outorgamento do Papa ou do Imperador.

Verdadera mente es llamado Rey aquel que con derecho gana el sennorio del rreyno, e puedese ganar por derecho en estas quatro maneras: la primera es quando por heredamiento hereda los rreynos [...]; la segunda es quando lo gana por avenençia de todos los del rreyno que lo escogen por sennor, [...] la terçera razon es por casamiento, [...] la quarta es por otorgamiento del papa o del enperador quando alguno dello faze Reyes en aquellas tierras en que a derecho de lo fazer: e los que ganan los rreynos en alguna de las maneras que desuso diximos son dichos verdadera mente Reyes. [...]" (TI, Ley IX).

Tanto a explicação sobre o significado da palavra monarca como a descrição das formas de adquirir o reino, concedem a noção da importância daquele que ocupa a direção política do reino.

Como governante, cabe a ele exercer as funções de governo. Estas são três: bélicas, jurídicas e religiosas (auxiliar a difusão da fé):

"E el Rey non tan sola mente era guiador e cabdillero de las huestes, e juez sobre todos los del rreyno, mas aun era sennor sobre las cosas espirituales [...]" (TI, Ley VI).

7 RUCOUOI, Adeline. "El Rey sabio: cultura y poder en la monarquia castellana medieval" Actas del III Curso de Cultura Medieval. Septembre, 199l, p. 77-87, p. 77. 
Particularmente é enfatizada na Partida Segunda a função jurídica. O caráter jurídico como primordial dentre todas as atribuições do Rei pode ser comprovado nas seguintes citações:

"asy ellos son tenudos de mantener e de governar en justiçia e en verdat a los de su sennorio" (T' I, Ley VI).

Posteriormente afirma:

"[...] para mantener e guardar las tierras en justiçia" (Titulo 1).

Ao determinar sua nomenclatura, forma de ganhar o reino e função, Alfonso X descreve a necessidade de um poder único capaz de interpretar o direito em função da coletividade. Dando assim uma explicação sobre a importância de sua existência.

\section{3 - 0 bem comum / a justiça}

O bem comum é o objetivo máximo do monarca. Sua política visa a coletividade. Deve sempre

"guardar la pro comunal de su pueblo que la suya misma, porque el bien a la rriqueza dellos es commo suyo, otrosy deven amar e onrrar a los mayorales, e a los medianos e a los menores, e a cada uno segunt su estado, [...] e meter amor e acuerdo entre su gente, e ser justiçiero dando a cada uno su derecho" (TI, Ley IX).

Ao monarca cabe abdicar de sua própria felicidade para maior: o bem comum, a felicidade de seu povo. É diferente do tirano que

"aman mas de fazer su pro, maguer sea a danno de la tierra, que la pro comunal de todos" (TI, Ley X).

Segundo o especialista em teoria política Walter Ullman, "Lo que iba en interés del pueblo no coincidía necesariamente con sus deseos. En esta concepción de la legislación parece radicar la esencia de toda forma teocrática de gobierno y derecho." ${ }^{\text {8 }}$

O monarca existe no reino para manter a visão do coletivo acima dos interesses individuais. Esta postura é confirmada por O'Callaghan: "In trying to maintain the kingdom in good estate, Alfonso X sought to achieve the common good (pro comunal). In numerous instances, he stressed that the acted for the good or benefit of the realm (pro de la tierra, pro del regno)". ${ }^{9}$

O bem comum só pode ser exercido através da justiça, que é a base da ação política do monarca. É o equilíbrio harmônico em função da coletividade:

"e esta es que la justiçia de nuestro Sennor Dios avie a dar en el mundo porque los omnes biviesen en paz e en amor" (T II, Ley VII).

A paz da coletividade justifica a existência da figura do monarca: "La conservación de la paz pública por medio de la protección era uno de los deberes más inportantes del gobernante teocrático". ${ }^{10}$

8 ULLMAN, Walter. Principios de gobiemo y politica en la Edad Media. Madrid: Alianza, 1985, p. 134.

9 O'CALLGHAN. Joseph F. The learned King. Philadelphia: University of Pensylvania, 1993, p. 20. 


\section{A justiça é caracterizada como}

"madre de todo bien, ca en ella caben todas las otras, e por ende arranca los coraçones de los omens, e faze que sean asy commo una cosa para bevir derecha miente segunt mandamiento de Dios e del sennor, departiendo e dando a cada uno su derecho asy commo meresçe e le conviene" (TV, Ley VIII).

Esta citação demonstra a necessidade da justiça para estabelecer a ordem. Ao monarca para exercê-la se exige mais do que aos outros homens de não possuir vícios e guardar as virtudes:

"porque son puestos en lugar de Dios en tierra par conplir la justiçia" (TV, Ley IX).

O monarca deve ser educado para cultivar bons costumes pois os erros costumam

"mas semejaria vengança que justiçia" (TV, Ley X).

A ira é um sentimento negativo:

"la yra del omne non dexa obrar la justiçia, que es cosa de Dios" (TV, Ley XII)

Sendo a justiça coisa de Deus, é do interesse de todos, mantê-la. A ira individual impede o homem de agir bem para a coletividade assumindo uma postura extremamente individualista, o que não é permitido ao dirigente do reino.

O monarca através da justiça congrega os homens em harmonia:

"mas le omne de todo esto non a anda para sy a menos de ayuda de muchos que lo busquen e le alleguen aquelas cosas quel convienen, e este ayudamiento non puede ser syn justiçia" (T I, Ley VII).

É portanto uma forma de dar paz ao seu território:

"porque sy desta uysa non lo feziere, non podrie fazer justiçia conplida miente, nin tener su tierra en paz nin mostrarse [...]" (TV, Ley XII).

A função de juiz indica a necessidade de haver apenas uma pessoa que é conhecedora da lei e da justiça. Concede a cada um seu direito por merecimento. Visa atender ao direito individual desde que esteja de acordo com a coletividade. O monarca impede arbitrariedades e, tornando-se justo, é amado pelo seu povo. Cabe a ele

"[...] meter amor e acuerdo entre su gente, e ser justiçiero dando a cada uno su derecho, e deven fiar mas en los suyos que en los estrannos, porque ellos son sus sennores naturales, $\theta$ non por premia" (TI, Ley IX).

Para atender este objetivo é necessário

"mantenerlos con justiçia e en verdat, e dar a cada uno su derecho segunt su meresçimiento" (TXIII, Ley XIII).

Manter em justiça significa impedir qualquer tipo de injustiça, distinguindo o certo do errado exercendo a função do grande pai que concede o direito de acordo com o merecimento.

É uma postura paternalista. É o responsável pelo bem estar destes:

10 ULLMAN, Walter, op. cit., p. 129. 
"Vicarios de Dios son los Reyes cada uno en su rreyno puestos sobre las gentes para mantenerlas en justiçia e en verdad quanto en lo tenporal, [...]" (T I, Ley V).

Alfonso X visa criar uma concepção de justiça e lei como algo necessário para a vida em comunidade, de forma a tornar a lei e o exercício do direito uma prática constante. A comparação justiça/castigo é substituída por justiça/vida em comum:

"[...] se crea uma conciencia juridica, se eleva el sentido y el amor al derecho y hasta, se diminuye los males de la ignorantia iuris, porque aprendidos los principios se intuyen los preceptos". ${ }^{11}$

\section{4- A ajuda dos sábios e a sapientia}

Alfonso X sempre esteve rodeado por um grupo de intelectuais conhecedores de vários campos do saber (Direito, Matemática, Astronomia, Literatura,...) e provenientes de culturas diferentes: muçulmanos, judeus e cristãos. A alcunha de Rei Sábio é inclusive proveniente desta sede de saber.

A presença de intelectuais na corte não significa apenas um afã de adquirir conhecimentos mas uma postura característica dos monarcas do século XIII que se rodearam de conhecedores do Direito, capazes de fornecer-lhes os subsídios necessários à formulação de uma linha teórica, proveniente do Direito Romano concedendo respaldo jurídico ao fortalecimento do poder real.

O sábio é aquele que acumula uma bagagem de conhecimento e pelo volume apreendido recebe esta denominação. A ele cabe difundir o conhecimento àqueles que dele se aproximarem: "Si el sabio está obligado a dejar correr su caudal de ciencia hacia los demás, a transmitirla, los otros deben mantenerse cerca del sabio para alimentarse de los bienes que éste comunica". ${ }^{12}$

O monarca castellano utiliza este sábio como seu assessor: "Todos los espejos político-morales de la época recompilan dichos y ejemplos de sábios y presentan la figura del sabio como ayo y supremo consejero del príncipe". ${ }^{13}$

$\mathrm{O}$ título da Ley $\mathrm{V}$ demonstra a importância dos sábios na formação do monarca:

"Commo el rey deve seer accuçioso en prender leer de los sabios e de los saberes que pudiere" (TV, Ley XV).

O conhecimento torna-se assim condição essencial para a formação de um bom monarca. Esta afirmação aparece também em outra citação:

"accucioso deve el Rey seer en aprender los saberes, ca por ello entendera las cosas de rraiz, e sobra meior obrar en ellas, e otrosy por saber leer sabre mejor guardar sos poridades e seer sennor dellas" (TV, Ley XVI).

Segundo Adeline Rucquoi, o conhecimento, para o monarca, transcende a função de aprimoramento pessoal. "[...] Mais elle l'obligeait, lui qui de par sa condition

11 BATLLE VÁZOUEZ, Manuel. "El estilo suasorio de las leyes de las Partidas". Anales de la Universidad de Murcia. Derecho. 1962-63, p. 61-76, p. 62.

12 MARAVALL, José Antonio. Estudios de Historia del Pensamiento Español. Edad Media. Madrid: Instituto de Estudios Politicos, 1954, p. 211.

13 FERNANDEZ, Luis Suárez. História de España Antigua y Medieval. Madrid: Rialp, 1986, p. 348. 
était plus [sage] que les autres hommes, non seulement à bien gouverner, mais encore à conduire son peuple vers cette même sagesse, le faisant sortir de l'ignorance, [qui est péché]". ${ }^{14}$

O aconselhamento exercido pelo sábio ocorre na medida em que este possui, por sua cultura, uma visão histórica de outras formas de atuação política através dos conhecimentos de épocas passadas dos quais retira condições para auxiliar a prática de bem governar.

A sabedoria é uma forma de atingir o conhecimento da sociedade como um todo, do bem viver no sentido de favorecer o desenvolvimento individual e coletivo para discernir com mais claridade o certo do errado e assim viver melhor. Por isso, é importante que aquele que governa esteja rodeado de sábios para impedir arbitrariedades.

Ao governar, Alfonso $\mathrm{X}$ afirma que é amparado por

"omnes bonos e sabidores quel consejen e le ayuden" (II, Ley I).

O conselho dos sábios é uma forma de impedir erros. São seus auxiliares na arte de governar:

"Otrosy deve aver omnes sennalados, e sabidores e entendudos, e leales e verdaderos quel ayuden el sirvan de fecho en aquellas cosas que son menester para su conseio e para fazer justiçia e derecho a la gente, [...]" (TI, Ley III).

Para justificar seus argumentos usa o seguinte critério de autoridade: os sábios:

"Segunt dixieron los sabios [...]" (TTV, Ley. I).

Em outra citação:

"Quatro maneras dixieron los sabios" (TTV, Ley II).

Através do respaldo dos sábios, Alfonso X justifica o uso da razão:

"Apuesta mente e con conplimiento de mazon" (T IV, Ley I).

Em outra citação a razão também aparece:

"Dos entendimientos dixieron los sabios que a el alma rrazonable, el uno para entender Díos

(...) e el otro para entender las obras en las tenporales." (TXII, Ley Primera),

Vemos, portanto, que a razão surge como um atributo necessário ao monarca e é viabilizada através do auxilio dos sábios. É muito freqüente a citação de Aristóteles, Salomão, os Evangelistas, etc. para ratificar as considerações feitas na lei, conforme demonstramos a seguir.

"E sobre esta rrazon fablo Aristotiles al Rey Alexandre" (TTV, Ley I).

Posteriormente Sêneca e Davi são citados:

"E sobre esto dixo Seneca el filosofo, que fue de Cordoba" (TI V, Ley II), "asy commo dixo el rey David [...] (T IV, Ley IV). "E por ende dixo un filosofo [...] (T IV, Ley V).

A justificativa dos sábios aparece na descrição sobre as mulheres:

14 RUCQUOI, Adeline. Histoire Médiévale de la Péninsule Ibérique. Paris: Seuil, 1993, p. 332. 
"dixo el Rey Salomon, el vino e las mugeres quando mucho lo usan fazen a los sabios rrenegar en Dios" (T V, Ley II).

A sabedoria e sua importância para fazer justiça:

"e en esta rrazon dixo el rey Davi consejando lhes a los Reyes que fuesen entendidos e sabidores, pues que ellos am de juzgar la tierra" (T V, Ley XVI).

Os ensinamentos do Rei Salomão a seu filho:

"e eso mesmo dixo el Rey Salomon su fijo, que los Reyes apriesen los saberes e non lo olvidasen, ca por ellos avian a juzgar e a mantener las gentes" (TV, Ley XVI).

Outro sábio também é nominalmente citado nas Partidas:

"E Vegeçio, que fue muy sabio cavallero, dixo que non conviene tanto a otro omne commo a Rey de saber los buenos saberes, porque la su sabidoria es muy provechosa a su gente, commo que por ella an a ser mantenidos con derecho" (TV, Ley XVI).

Os sábios antigos servem também de exemplos para os reis:

"ca los sabios antiguos, que pararon mientes en todas las cosas, mostraron que los Reyes deven aguardar todo esto que deximos, de manera que lo fagan muy apuesta mente, e esto por seer meior acostunbrados e mas nobles, que es cosa que conviene mucho" (T V, Ley IV).

Alfonso X utiliza a figura dos sábios como suporte para sua política. Estes, pelo conhecimento que possuem, são inquestionáveis. Estão rodeando o monarca, auxiliam o governo para que todos os atos do rei sejam conscientes, sábios e sirvam de exemplos.

\section{5 - A formação do monarca e o preparo para a virtude}

O monarca recebe um tipo de educação especial já que é destinado a um cargo impar na sociedade:

"Enperadores e Reyes son mas nobles personas en onrra e en poder [...]" (TI). erros:

A formação do monarca visa desenvolver a justiça e amor para não cometer

"E por ende el Rey deve guardar su onrra, de guysa que todavia acresa en ella e non la mengua" (T III, Ley III).

Sua atitude deve ser a melhor possivel, pois o castigo está presente principalmente para ele:

"e otrosy todo onme que esto faze yerra, quanto mas el Rey, a quien Dios dara pena porque obro mal e escasa mente de los que el le dio" (TIII, Ley IV).

$O$ castigo também encontra-se na seguinte citação:

" $\mathrm{E}$ al que por sus malos pecados asy non lo fiziese, darle a Dios el contrario desto, e serie su pena mayor que dotro omne, segunt le demostrara el grant amor en darle onrra e poder" (TII, Ley II).

Para entender melhor a formação que é exigida do governante, tomamos as próprias palavras da Segunda Partida. Deve cultivar alegria de espírito pois

"la yra del Rey es mas fuerte e mas dannosa que la de los otros omnes" (TV, Ley XI). 
Através das regras de etiqueta, deve adquirir bons costumes:

"costunbres e maneras deve aver el Rey muy buenas [...] sy non fuesen buenas, [...] menguarie mucho en su nobleza e en su apostura" (TV, Ley VI).

O monarca deve ser comedido ao falar:

"non conviene a el Rey de seer muy fablador, nin dixiese a muy grandes vozes lo que oviese e dezir, fueras ende en lugar do conviniese", (TIV, Ley II).

Sobre o falar deve

"ca la verdat es cosa derecha e egual [...] deve fablar en pocas palabras [...] por eso non lo deve fazer en manera que non muestren bien e abierta mente lo que dixiere" (TIV, Ley III).

Deve ter formação primorosa:

"Acuçioso deve el Rey seer en aprender los saberes, ca por ellos entendera las cosas de rrayz, e sabra meior obrar en ellas, e otrosy por saber leer sabra mejor guardar sus poridades e seer sennor dellas" (TV, Ley XVI).

Toda a educação do monarca visa auxiliar na construção de um homem possuidor de bons modos, cultura e preparo para que sua prática reflita esta formação para o bem de seu reino. Deve domar os instintos e praticar a arte da virtude, ponderação e equilíbrio. Só assim é capaz de impor a justiça.

\section{6 - Comparação e caráter didático}

$\mathrm{O}$ caráter didático estará presente em toda a obra. Seu objetivo é facilitar a explicação de determinada terminologia, é facilitar a exposição. Assim a presença de analogias também visa exemplificar determinados conteúdos. Por exemplo, a visão única do monarca é comparada com o corpo humano:

"E natural mente dixieron los sabios que el Rey es cabeça del rreyno; asy como de la cabeça naçen los sentidos por que se mandan todos los mienbros del cuerpo, bien asy por el mandamiento que naçe del Rey, que es senor e cabeça de todos los del rreyno, se deven mandar, e guiar e aver un acuerdo con el para obedescer-le e anparar, e guardar e endresçar el rreyno onde el es alma e cabeça, e ellos los mienbros" (TI, Ley V).

Em outra passagem é a analogia com a natureza que se manifesta:

"el rregno es commo huerta, e el pueblo commo arboles, e el Rey es sennor della," (TX, Ley XIII).

Para descrever que o monarca não deve utilizar palavras "villanas", Alfonso X usa também a analogia:

"Ca bien asy commo el cantaro quebrado se conosçe por el sueno, otrosy el seso del omne es conosçido por la palavra" (TIV, Ley V).

Outra forma de utilização do caráter didático é ao corrigir os erros:

"Rey tanto quier dezir commo rregla, ca asy commo por ella se conosçen todas las torturas e se enderesçan, asy por el Rey son conoçidos los yerros e enmendados" (TI, Ley VI). 
Alfonso X utiliza o erro para justificar a sua força. Ao caracterizar o tirano visa inculcar em seus leitores a visão positiva do rei através de uma crítica ao não-rei, ou seja, o tirano. 0 tirano não ama seu povo mas,

"amam mas de fazer su pro maguer sea a danno de la tierra, que la pro comunal de todos" ((TI, Ley X).)

$\mathrm{E}$, diferente dos monarcas, não utiliza o auxilio dos sábios:

"Syempre punnaron los tiranos de estigar a los poderosos, e de matar a los sabidores" (TI, Ley $\mathrm{X})$.

Faz parte do universo simbólico medieval a visão como forma de aprendizagem, conforme caracteriza Alfonso X:

"Veer es el primero de los çinco sentidos de fuera de que fizieron semejança Aristotiles e los otros sabios al pueblo;" (TXIII, Ley Primera).

O traje é um aparato necessário para revelar simbolicamente a hierarquia social, diferenciando os homens comuns do monarca. Ao vê-lo você distingue o indivíduo, hábito fundamental em uma sociedade de iletrados.

Ao descrever o traje a educação adquire o significado do conhecimento através da visão. $O$ ver significa uma forma de apreender a realidade através do sentido mais fácil. Assim a diferenciação do traje significa o status social:

"vestiduras fazen mucho conosçer a los omnes por nobles o por viles" (TV, Ley V).

Os sábios estabeleceram um tipo de roupagem para o monarca:

"e los sabios antygos esta bleçieron que los Reyes vestiesen pannos de seda con oro e con piedras preçiosas, porque los omnes los pudiesen conosçer luego que los viesen a menos de perguntar por ellos [...]" (TV, Ley V).

Luis Suárez Fernandez corrobora com palavras atuais o pensamento de Alfonso $\mathrm{X}$ : "La alegorización y moralización de cuanto se ve en el mundo constituye el procedimiento para penetrar en el saber de éste, porque todo saber es, fundamentalmente, un saber de símbolos". ${ }^{15}$

Uma outra forma de saber é través de exemplos, ou seja, utilizando a História:

"e aun por el leer puede el mesmo saber los fechos granados que pasaron, de que aprendera muchos buenos enxienplos" (TV, Ley XVI).

Podemos reparar que a educação na Partida Segunda significa uma forma de descrever de forma didática um determinado conteúdo. Ao usar exemplos, analogias, utilizar os sentidos e descrever didaticamente, Alfonso $\mathrm{X}$ objetiva tornar sua obra mais compreensivel. Dá uma explicação fácil para facilitar sua apreensão.

\section{7 - $O$ apoio e auxílio no governo}

A hierarquia palaciana é explicada na Partida Segunda como necessária ao bom andamento do poder. Alfonso $\mathrm{X}$ descentraliza a função do poder em microcosmos subordinados:

15 FERNANDEZ, Luis Suárez, op. cit., p. 346. 
"E duc tanto quiere dezir commo cabdiello guiador de hueste, que toma este ofiçio [...] $\mathrm{E}$ conde tanto quiere dezir commo conpannero [...] E marques tanto quiere dezir commo sennor de alguna grant tierra [...] e iuge tanto quiere dezir commo iudgador [...] $\mathrm{E}$ visconde tanto quier dezir como ofiçial" (TI, Ley XI).

Vimos como caraterizou minuciosamente a função de cada um deles para justificar o cargo daqueles que o auxiliam na arte de bem governar. É uma forma de justificar a presença de outros administradores na hierarquia administrativa.

Devem agir com honra para o bem de seu povo:

"maguer sean grandes señores, non pueden fazer cada uno dellos mas que un omnr por que fue mester que oviesse en su corte omne onrrados [...] e de que se enbergonnasen las gentes en aquellas cosas que ellos oviesen de veer por mandado dellos" (TI, Ley XII).

Ao povo também cabe auxiliar o monarca:

"Commo el pueblo deve bien consejar e servir al Rey, e guardarse del contrario desto que es dicho" (TXIII, Ley VII).

Ao afirmar a necessidade de todos para o bom governo, Alfonso $\mathrm{X}$ compartilha, com cada um, parte do poder. Todos possuem uma função no reino e, de certa forma, são cúmplices de toda a política do monarca. $\mathrm{O}$ caráter de cumplicidade e participação faz com que cada um sinta-se integrado na coletividade aceitando as regras contidas na mesma.

\section{Conclusão}

Os ítens abordados anteriormente descrevem claramente a utilização de estratégias, por parte de Alfonso X, para que sua legislação seja esclarecida e aceita. Caracteriza seu poder temporal como proveniente de Deus e sua esfera de atuação, restrita ao mundo terreno.

Apesar de ser rei, como qualquer mortal está sujeito a erros e castigos. Deve, portanto, rodear-se de sábios e receber uma formação especial, de forma a adquirir sabedoria para governar com justiça. Esta significa o exercício do bem comum, a plenitude da vida em comunidade. O monarca deve abdicar de seu próprio interesse em função da coletividade.

A linguagem utilizada para explicar esta concepção de poder é clara, didática, racional. Quer convencer da necessidade de um dirigente único, distinto, que vise o bem comum e a justiça. A lei não significa, portanto, uma imposição mas uma forma de orientar a vida em comum.

Segundo Francisco López Estrada, as Partidas não é somente um livro para juristas mas "[...] una obra que pudo ser leída junto con los tratados de moralidad y de buenos consejos, tan abundantes en esta época, destinados a los reyes, príncipes, grandes señores y caballeros que quisieran conocer los principios del trato en las relaciones politicas y sociales de las cortes. [...] Así se llegaba a formular, entre las menciones propiamente legales, los principios de una virtud cortés, de carácter civil, en lo que esta inclinaba hacia una conducta personal y política, establecida en el cauce de unas normas de justicia y pacífica convivencia social. ${ }^{16}$

16 LACARRA, María Jesús e LOPES ESTRADA, Francisco. Origenes de la prosa. Madrid: Júcar, 1993, p. 136. 
Concordamos com a postura de Francisco López Estrada afirmando que a Segunda Partida tem uma postura didática e moralizante. É um livro de exemplos que não é lido como uma imposição mas como regras que devem ser seguidas em benefício da comunidade na qual todos encontram-se inseridos. Ao assumir este estilo de vida, cada um incorpora a necessidade da existência de monarca como 0 que foi caracterizado, de justiça e direito, fortalecendo assim a figura do rei segundo a concepção de Alfonso X. 